\title{
Persistence of social investigatory behavior in the male rat: Evidence for long-term memory of initial copulatory experience
}

\author{
D. H. THOR and W. R. HOLLOWAY \\ Edward R. Johnstone Training and Research Center, Bordentown, New Jersey assos
}

\begin{abstract}
The duration of active social investigation by sexually mature male rats, following exposure to a novel conspecific, was investigated to assess the influence of former social experience. In Experiments 1 and 2, pretest social isolation of older males with extensive heterosexual experience and of younger males with limited heterosexual experience failed to affect their subsequent persistence in social investigation. Older and serually experienced rats, however, engaged in significantly less investigatory behavior than did younger, sexually inexperienced males. Experiments 3,4 , and 5 demonstrated that this difference was associated with prior copulatory experience. A single copulatory series with either an intact female or a hormone-primed castrate female effected a significant and sustained decrease in social investigatory behavior. The results are interpreted as demonstrating a form of long-term memory for associations formed during initial copulatory experience.
\end{abstract}

An unfamiliar conspecific is an attractive social stimulus for the mature laboratory rat and is intensively investigated when introduced into the animal's cage. This investigation may culminate in aggression, sexual activity, or passive acceptance of the intruder. Duration of active social investigation is determined in part by sex of the subject; males investigate significantly longer than females, and intact males investigate significantly longer than castrate males (Thor, 1980). This sex difference in persistence suggests that social investigation is functionally related to a greater need in males to confirm identity preliminary to aggression or copulation (Carr, 1974; Thor, 1979).

The following experiments looked first at the influence of prior social isolation on the persistence of social investigation by mature male rats when exposed to a novel conspecific and then at the influence of prior copulatory experience upon social investigation. In each experiment, the social investigatory behavior of the subject was observed after the placement of an unfamiliar stimulus animal in the subject's cage. Active investigatory behavior was recorded until the subject met a neglect criterion of $30 \mathrm{sec}$ with no investigation.

\section{EXPERIMENT 1}

This experiment was conducted to determine whether an isolation interval of 8 days significantly

We thank R. K. Lore of Rutgers University for the animals used in Experiment 1 and D. L. Hoats of the Johnstone Center for technical assistance with the apparatus. Requests for reprints may be addressed to D. H. Thor, Research Department, Johnstone Training \& Research Center, Bordentown, New Jersey 08505. increases or decreases persistence in social investigation by mature males prior to a criterion of neglect.

\section{Method}

Subjects and Apparatus. Subjects were 24 male Long-Evans rats obtained from the Department of Psychology at Douglass College, Rutgers University. All were successful breeders, 8-10 months of age, and had been maintained in pairs. Ten mature castrate females served as social stimuli. A hand-held switch panel was used to record durations of social investigation, copulatory mounting, and aggressive behavior. Release of any switch closure activated a countdown timing circuit that was reset upon any switch closure that occurred within $30 \mathrm{sec}$. Upon completion of a $30-\mathrm{sec}$ interval with no switch contact, a tone signal indicated termination of the observation. An event recorder was used to provide a paper-tape record of switch closures over time. All observations were made at the same time of day, during the normally dark period of a reversed light-dark cycle. Lab chow and water were freely available throughout.

Procedure. Eight males were assigned to each of three treatment groups on the basis of a pretest measure of persistence in social responding to a castrate female. The pretest was given individually after $24 \mathrm{~h}$ adaptation to a clean, $41 \times 51 \times 22 \mathrm{~cm}$ polypropylene pan cage. A stimulus female was placed in the center of the cage, and the subject's social behavior was recorded to a criterion of $30 \mathrm{sec}$ with no further social behavior directed toward the social stimulus. Investigatory behavior included sniffing, following, grooming, or nosing of the castrate female (Grant \& Mackintosh, 1963). Copulatory behavior was defined as mounting the stimulus female; aggressive behavior was defined as biting attack or aggressive posturing toward the stimulus female (see Barnett, 1975). A posttest, identical to the pretest, followed an 8-day interval of social isolation (isolate group), an 8-day interval of cohabitation with another intact male (paired-male group), or an 8-day interval of cohabitation with a castrate female (paired-female group). In the paired groups, the subject's partner was removed $1 \mathrm{~h}$ before the posttest.

\section{Results and Discussion}

Pre- and posttest means and standard errors of each measure for each group are presented in Table 1 . 
Table 1

Mean Seconds (and SEs) of Social Behavior (Experiment 1)

\begin{tabular}{|c|c|c|c|c|c|c|c|}
\hline \multirow[b]{3}{*}{ Behavior } & & \multicolumn{6}{|c|}{ Male Group } \\
\hline & & \multicolumn{2}{|c|}{ Isolate } & \multicolumn{2}{|c|}{$\begin{array}{c}\text { Paired } \\
\text { Male }\end{array}$} & \multicolumn{2}{|c|}{$\begin{array}{l}\text { Paired } \\
\text { Female }\end{array}$} \\
\hline & & Mean & SE & Mean & SE & Mean & SE \\
\hline \multirow{2}{*}{ Investigation } & Pretest & 66 & 6 & 77 & 15 & 76 & 13 \\
\hline & Posttest & 69 & 12 & 81 & 14 & 92 & 22 \\
\hline \multirow{2}{*}{ Copulation } & Pretest & 10 & 4 & 6 & 2 & 6 & 2 \\
\hline & Posttest & 5 & 2 & 5 & 2 & 5 & 2 \\
\hline \multirow{2}{*}{ Aggression } & Pretest & 4 & 4 & 1 & 1 & 1 & 1 \\
\hline & Posttest & 0 & 0 & 1 & 0 & 0 & 0 \\
\hline
\end{tabular}

Since the majority of subjects in each group failed to display any aggression, no further analysis of aggression data was undertaken. Analyses of variance of square-root transformed scores (groups $\times$ pre-/ posttest) were computed with the investigation and copulation data. All main effects and interactions were nonsignificant $(p>.05)$. Social isolation for 8 days did not influence the persistence of social interaction by mature male rats when exposed to a castrate female in the present test situation.

\section{EXPERIMENT 2}

Males used in prior experiments demonstrating social isolation effects (Latané \& Steele, 1975) were considerably younger than the males used in Experiment 1. Therefore, Experiment 2 was conducted to determine whether social isolation of young male rats, for an interval of 20 days, significantly affects their social investigation of novel castrate females when compared with young male rats housed in groups.

\section{Method}

Subjects and Apparatus. Subjects were 32 laboratory-reared Long-Evans male rats, 57-59 days of age at the start of the experiment. Since weaning at 25 days, all had been maintained in samesex groups of 6-8 per cage with ad-lib food and water. Sixteen castrate female rats served as social stimuli.

Procedure. One group of 16 male subjects were maintained in four cages $(41 \times 51 \times 22 \mathrm{~cm})$ with four subjects per cage (social group). A second group of 16 male subjects were housed one per cage (isolate group). Lab chow and water were freely available throughout. After 20 days, each subject was tested in its home cage, as described in Experiment 1. Each female castrate was presented to one male in each group.

Table 2

Mean Seconds (and SEs) of Social Behavior (Experiment 2)

\begin{tabular}{lrrrrr} 
& \multicolumn{4}{c}{ Male Group } \\
\cline { 2 - 5 } \cline { 4 - 5 } Behavior & Mean & SE & Mean & SE \\
\cline { 2 - 5 } \cline { 4 - 5 } Investigation & 192 & 16 & 199 & 13 \\
Copulation & 4 & 1 & 7 & 2 \\
Aggression & 15 & 6 & 4 & 2 \\
\hline
\end{tabular}

\section{Results and Discussion}

Means and standard errors of each category of behavior for each group are presented in Table 2.

Mean differences were nonsignificant $(p>.05)$ for investigation, copulation, and aggression. Thus, social isolation of 8 or 20 days' duration did not influence the persistence of investigation of a novel conspecific in the present situation.

Mean investigations times of young males in both social conditions were, however, considerably longer than the same measures taken with older males in Experiment 1. The data of Experiments 1 and 2 were therefore collapsed over social and isolation groups for an age group comparison. Mean differences were significant for investigation $[\mathrm{t}(54)=8.65, \mathrm{p}<.001]$ and for aggression $[t(54)=2.6, p<.05]$ and nonsignificant for copulation. Younger males investigated more than twice as long as did older males (means = 195.9 vs. $74.0 \mathrm{sec}$ ) and were more aggressive than older males (means $=9.8$ vs. $.2 \mathrm{sec}$ ).

\section{EXPERIMENT 3}

The results from Experiments 1 and 2 indicate that social isolation for up to 20 days does not influence investigation of a novel conspecific. The large difference in investigation time between the old (10 months) and young ( 80 days) subjects could be related to their ages (Thor, Wainwright, \& Holloway, in press); however, a notable difference between the young ( 80 days) and old (10 months) rats used in Experiments 1 and 2 is their sexual experience. The younger animals had been housed (after weaning) either in same-sex groups or in isolation. All were naive sexually. The older rats, on the other hand, had considerable sexual experience with intact females and with females brought into behavioral estrus by hormonal manipulations. The consideration, then, is whether the less persistent investigation by older rats may be attributed to age or if it is due to their prior sexual contact with females. It may be noted that others, using a different measure of sociability (time that paired rats are in physical contact), have failed to observe an influence of sexual experience on social affiliation (Sloan \& Latané, 1974).

Experiment 3 was conducted to determine whether prior copulatory experience of males with intact females significantly alters their social investigatory behavior. Based on the results of Experiments 1 and 2, it was hypothesized that young males, given several consecutive exposures to intact females, would thereafter investigate a novel conspecific significantly less than would young males of the same age exposed to nonreceptive, castrate females.

\footnotetext{
Method

Subjeets and Apparatus. Subjects were 16 of the Long-Evans males used in Experiment 2. At the start of this experiment, all were naive sexually and were approximately 90 days of age. Twenty-
} 
four castrate females were used as social stimuli or as cohabitants with male control subjects. Twenty-four intact, virgin females, 60 80 days of age, were used as copulatory partners. The timing and recording equipment was that used in Experiment 2.

Procedure. One group of eight male subjects was housed individually and presented with an intact female cohabitant at weekly intervals for 3 weeks. A control group of eight males was housed individually and presented with a castrate female cohabitant at each week for 3 weeks. Each subject in each group was thus exposed to three females (either intact or castrate), cohabiting with each for 1 week. Pretreatment social investigation tests were given each day for 3 days prior to female exposure; posttreatment tests were given each day for 3 days beginning 4 days following exposure to females. Each test was conducted as described in Experiment 1.

\section{Results and Discussion}

All males exposed to intact females engaged in copulation, as evidenced by consequent pregnancies. Six males impregnated three females, and two males impregnated two of the three females with whom they cohabitated.

Medians of three pretreatment and of the three posttreatment scores for each subject were used in all statistics to decrease variance attributable to occasional extreme scores. Group means and standard errors of investigation scores are presented in Table 3. Social investigatory behavior on pre- and posttreatment tests differed significantly $[F(1,14)=13.08$, $\mathrm{p}<.01]$, with lower mean scores on the posttreatment testing. The interaction of groups $x$ test was also significant $[F(1,14)=8.39, p<.01]$. Mean scores for males housed with intact females decreased significantly $[t(7)=4.96, p<.005]$; the decrease for males housed with castrate females was nonsignificant.

Male exposure groups also differed in their copulation times $[F(1,14)=8.42, p<.01]$; males housed with intact females engaged in more mounting behavior (mean $=5.1 \mathrm{sec}$ ) when exposed to female castrates than did males housed with female castrates (mean = $1.4 \mathrm{sec}$ ). The pre- and posttreatment mean difference and the interaction were nonsignificant.

Males housed with castrate females were more aggressive $[F(1,14)=4.80, p<.05]$ during testing than were males housed with intact females (means $=9.2$ vs. $2.7 \mathrm{sec}$ ). However, males housed with castrate females were initially more aggressive (mean $=18.0 \mathrm{sec}$ ) than were males housed with intact females (mean = $5.2 \mathrm{sec}$ ), and this difference contributed to the interaction of groups $\times$ test $[F(1,14)=4.63, p<.05]$; on

Table 3

Mean Seconds (and SEs) of Investigatory Behavior Before and After Exposure to Intact or Castrate Females (Experiment 3)

\begin{tabular}{ccccc}
\hline & \multicolumn{3}{c}{ Social Investigation } \\
\cline { 2 - 5 } Exposure & Before Exposure & After Exposure \\
\cline { 2 - 5 } & Mean & SE & Mean & SE \\
\hline To Castrate Females & 167 & 19 & 158 & 13 \\
To Intact Females & 187 & 14 & 112 & 14 \\
\hline
\end{tabular}

posttreatment test, the male groups did not differ significantly.

The results confirm the finding of increased mounting by males that have had copulatory experience (Sloan \& Latané, 1974). Furthermore, time of social investigation prior to the criterion of neglect was longer for virgin males than for nonvirgin males of the same age. Sloan and Latane (1974) did not find significant differences in contact time of sexually experienced and sexually inexperienced males exposed to tethered, nonreceptive females (Experiments 2 and 3).

The reliable mean difference in social investigation by males exposed to receptive females and males exposed to nonreceptive females suggests that copulatory experience decreases subsequent social investigatory behavior when males encounter a novel castrate female. It may be assumed that the male rat, having formed the association between a variety of social cues (olfactory, movement, tactual) relating to behavioral estrus of the female and sensory stimulation from copulation, thereafter demonstrates greater efficiency in investigation of a novel conspecific-that is, duration of social investigatory behavior prior to criterion will be significantly less for males with copulatory experience than for males without copulatory experience.

\section{EXPERIMENT 4}

This experiment was conducted to determine whether sexually experienced males differ from sexually inexperienced males in their persistence of social investigation when exposed to a novel juvenile conspecific. It was hypothesized that juveniles would be investigated significantly longer prior to criterion by virgin males than by nonvirgin males, that is, that the difference in duration of investigation observed in Experiment 3 can be generalized to juvenile conspecifics.

\section{Method}

Subjects and Apparatus. Subjects were the 16 Long-Evans males used in Experiment 3. During the interim ( 2 weeks) since they were last tested, each subject had been maintained in a separate cage. Sixteen female juveniles, 20 to 25 days of age, were used as social stimuli. The test apparatus was that used in Experiment 3.

Procedure. Each of the eight sexually experienced subjects and each of the eight sexually inexperienced subjects was exposed to juveniles in its home cage. Exposures were made daily to a different juvenile at the same time of day for 3 days. Each exposure test was conducted as described in Experiment 1 to a neglect criterion of $30 \mathrm{sec}$.

\section{Results and Discussion}

Means and standard errors of total investigation time by each group prior to criterion on each successive daily test are presented in Table 4 .

Sexually inexperienced males investigated juveniles longer $[F(1,14)=16.25, p<.005]$ than did the sexually experienced males. Tests and the interaction of 
Table 4

Mean Seconds (and SEs) of Investigation by Sexually Experienced and Inexperienced Males (Experiment 4)

\begin{tabular}{|c|c|c|c|c|c|c|}
\hline \multirow[b]{2}{*}{ Group } & \multicolumn{2}{|c|}{ Daily Test $\mathbf{i}$} & \multicolumn{2}{|c|}{ Daily Test 2} & \multicolumn{2}{|c|}{ Daily Test 3} \\
\hline & Mean & SE & Mean & SE & Mean & SE \\
\hline Experienced & 85 & 7 & 91 & 8 & 89 & 15 \\
\hline Inexperienced & 119 & 14 & 141 & 11 & 154 & 24 \\
\hline
\end{tabular}

groups $x$ tests were nonsignificant. Copulatory mounts were occasionally attempted by some males, and some aggressive grooming was observed, but the majority of subjects engaged only in investigatory behavior. Insufficient copulatory and aggressive data were available for statistical analysis.

The reliable difference between equal-age male groups differing in prior copulatory experience extends the findings of Experiment 3. Juveniles, as well as mature castrate females, are investigated for longer intervals prior to the neglect criterion by virgin males than by nonvirgin males. Apparently, persistence in social investigation, as determined by the present method, is sensitive to former copulatory experience. This change in the male's response to a novel conspecific appears to be relatively permanent since the difference was evident following a 2-week delay between Experiments 3 and 4. Males with copulatory experience appear to have learned a social discrimination that allows a more efficient determination of the social significance of a novel conspecific. This interpretation suggests that active social investigation by mature males may be a form of discriminative behavior preliminary to copulation and that social investigatory behavior is intimately linked to reproductive behavior (see Beach, 1956, 1976; Carr, 1974).

\section{EXPERIMENT 5}

This experiment was conducted to determine how many copulatory series, with intact females or with hormone-primed castrate females, are required to demonstrate a significant decrease in persistence of social investigatory behavior by mature male rats.

\section{Method}

Subjects and Apparatus. Subjects were 27 Long-Evans male rats, 68-70 days of age at the start of the experiment. Since weaning at 25 days, all had been maintained in groups of four to six animals per cage. None had been exposed to females since weaning. Twenty-seven intact females and 18 castrate females were used as cohabitants. An additional group of 18 castrate females were used as social stimuli during testing.

Procedure. Each subject was housed individually in a polypropylene pan cage $(41 \times 51 \times 22 \mathrm{~cm})$ with pine-chip and Sani-cel litter. Lab chow pellets and water were available throughout.

A preexposure test with a castrate female social stimulus animal was made to form three groups matched on the basis of their persistence in investigation. This test was conducted $24 \mathrm{~h}$ after assignment to individual cages. One group of nine males, designated as Group IF, was subsequently exposed to intact females. A second group of nine males, designated as Group $\mathrm{CF}$, was subsequently exposed to castrate females. A third group of nine males, designated as Group HPCF, was subsequently exposed to hormoneprimed castrate females. In sum, two experimental groups were scheduled for sexual contact with receptive females, while a control group (Group CF) was scheduled for nonsexual contact with castrate females.

After each 5-day interval of cohabitation, the nine intact females were marked and set aside to later determine whether they had been impregnated by the male subject and thus to verify the occurrence of a copulatory series. Hormone-primed castrate females were periodically observed after a placement in the subjects' cages to verify sustained copulation by the male subject. Each hormone-primed female had received one cycle of estradiol benzoate and progesterone injections followed by exposure to stud males on the week prior to initial use as sexual lures (initial hormone treatment followed by exposure to males is generally not as effective as subsequent treatment and exposure cycles in eliciting receptive behaviors). Subjects in Group CF were exposed to a castrate female for 5 days each week (different female each week during the time that the other groups were exposed to intact or hormone-primed females).

Intact females, hormone-primed castrate females, and castrate female cohabitants were exposed to the male subjects for 5 consecutive days on each consecutive week for 3 weeks. Each subject therefore cohabited with three different females of a single category. On the 7th day of each week, each subject was tested with a novel, castrate female social stimulus. This test was identical to the pretest and was conducted as described in Experiment 1.

\section{Results and Discussion}

One subject in Group IF failed to impregnate the first two females and was discarded. Another subject in Group HPCF failed to copulate to ejaculation and was also discarded. Data from all other subjects were included in the statistical analysis.

Means of Groups IF and HPCF (sexual experience groups) failed to differ significantly on any test, and the data from these groups were therefore combined. A two-way analysis of variance (groups $\times$ tests) was then computed with investigation time scores. Groups differed significantly $[F(1,23)=49.57$, $\mathrm{p}<.001]$, as did tests $[\mathrm{F}(3,69)=10.72, \mathrm{p}<.001]$ and the groups $x$ tests interaction $[F(3,69)=6.06, p<$ $.01]$. Means and standard errors are presented in Table 5.

A one-way analysis of variance across tests was nonsignificant for the group of males exposed only to nonreceptive castrate females. A one-way analysis of variance across tests for sexually experienced males was significant $[F(3,45)=23.80, p<.001]$, and a post hoc test for paired-mean comparisons (Tukey HSD) indicated significant mean differences between Pretest and Posttest $1(\mathrm{p}<.05)$, Pretest and Posttest $2(p<.01)$, and Pretest and Posttest $3(p<.01)$. Posttests 1 and 2 also differed significantly $(\mathrm{p}<.05)$.

These results may be interpreted as indicating that one copulatory series by a sexually mature male is sufficient to decrease subsequent social investigatory behavior of a nonreceptive conspecific. Virgin males, housed only with castrate females, continue to engage in significantly longer bouts of social investigation than do nonvirgin males. 
Table 5

Mean Seconds (and SEs) of Investigatory Behavior Before and After Successive Exposures to Intact and Castrate Females (Experiment 5)

\begin{tabular}{lrrrrrrrrr}
\hline & \multicolumn{2}{c}{ Preexposure Test } & \multicolumn{2}{c}{ Postexposure Test 1 } & \multicolumn{2}{c}{ Postexposure Test 2 } & \multicolumn{2}{c}{ Postexposure Test 3 } \\
\cline { 2 - 9 } Exposure & Mean & SE & Mean & SE & Mean & SE & Mean & SE \\
\hline To Nonreceptive Females & 178 & 17 & 204 & 17 & 152 & 15 & 202 & 11 \\
To Receptive Females & 172 & 8 & 135 & 10 & 86 & 5 & 109 & 10 \\
\hline
\end{tabular}

\section{GENERAL DISCUSSION}

The combined results indicate that copulatory experience of the male rat reliably decreases persistence of subsequent social investigation when the male is exposed to novel conspecifics. That is, the duration of intense, investigative behavior, normally seen when a strange conspecific is placed in the home cage of the subject, is markedly decreased from precopulatory level. Conceivably, the sexually inexperienced male must engage in prolonged social investigation since the basis for making a discriminative decision (the learned association between estrous cues and copulatory stimuli) is lacking in prior social experience. A single copulatory series with an intact or hormone-primed estrous female is apparently sufficient to effect this readily observed change in male behavior. Hence, initial copulatory exposure, at least for the male rat, may be viewed as a significant learning experience.

Stimuli from females, notably olfactory cues, may function primarily as attractants for sexual rapprochement, and such rapprochement appears to be an integral part of the mating pattern (see Beach, 1976; Carr, 1974). Additionally, attraction to nonsexual, social stimuli from conspecifics is also decreased by former sexual experience. The latter observation emphasizes the discriminative learning of social cues associated with copulatory stimuli.

In the terminology employed by Carr (1974, p. 109), a male rat that is polygamous (prior copulation with a number of different female partners) and that has gained savoir faire (prior learning that some females readily initiate and/or readily accept sexual advances), no longer engages in the protracted social investigative behavior commonly seen in males lacking copulatory experience. It remains to be seen whether monogamous or polygamous males lacking savoir faire (males exposed only to estrous females) also display a generalized decrease in social investigatory behavior. In Experiments 3 and 5, males were exposed to normally cycling females. An element of the social learning experience may thus include discriminating distinctive movement and/or chemosensory cues (proceptive and receptive) that are highly correlated with ovarian state.

\section{REFERENCES}

BARnetT, S. A. The rat: A study in behavior (Rev. ed.). Chicago: University of Chicago Press, 1975.

Beach, F. A. Characteristics of masculine "sex drive." In M. R. Jones (Ed.), Nebraska Symposium on Motivation. Lincoln: University of Nebraska Press, 1956.

ВеАсн, F. A. Social attractivity, proceptivity, and receptivity in female mammals. Hormones and Behavior, 1976, 7, 105-138.

CARR, W. J. Pheromonal sex attractants in the Norway rat. In L. Krames, P. Pliner, \& T. Alloway (Eds.), Advances in the study of communication and affect: Nonverbal communication (Vol. 1). New York: Plenum Press, 1974.

Grant, E. C., \& Mackintosh, J. H. A comparison of the social postures of some common laboratory rodents. Behaviour, 1963, 21, 246-259.

Latané, B., \& Steele, C. The persistence of social attraction in socially deprived and satiated rats. Animal Learning \& Behavior, $1975,3,131-134$.

Sloan, L., \& LAtané, B. Sex and sociability in rats. Journal of Experimental Social Psychology, 1974, 10, 147-158.

Thor, D. H. Olfactory perception and inclusive fitness. Physiological Psychology, 1979, 7, 303-306.

THOR, D. H. Testosterone and persistence of social investigation in laboratory rats. Journal of Comparative and Physiological Psychology, 1980, 94, 970-976.

Thor, D. H., Wainwright, K. L., \& Holloway, W. R. Persistence of attention to a novel conspecific: Some developmental variables in laboratory rats. Developmental Psychobiology, in press.

(Manuscript received May 11, 1981; revision accepted for publication August 5, 1981.) 